\title{
A mixed methods pilot study with a cluster randomized control trial to evaluate the impact of a leadership intervention on guideline implementation in home care nursing
}

\author{
Wendy A Gifford*1, Barbara Davies ${ }^{1}$, Ian D Graham³ ${ }^{3}$ Nancy Lefebre², \\ Ann Tourangeau ${ }^{4}$ and Kirsten Woodend ${ }^{1}$
}

Address: ${ }^{1}$ University of Ottawa, Faculty of Health Sciences, School of Nursing, 451 Smyth Road, Ottawa, ON, K1H 8M5, Canada, ${ }^{2}$ Saint Elizabeth Health Care, 90 Allstate Parkway, Toronto, ON, Canada, ${ }^{3}$ Canadian Institute of Health Research, 160 Elgin Street, 9th Floor, Ottawa, ON, Canada and ${ }^{4}$ University of Toronto, Faculty of Nursing, 155 College Street, Toronto, ON, Canada

Email: Wendy A Gifford* - wgifford@rogers.com; Barbara Davies - bdavies@uottawa.ca; Ian D Graham - IGraham@cihr-irsc.gc.ca; Nancy Lefebre - knowledge@saintelizabeth.com; Ann Tourangeau - ann.tourangeau@utoronto.ca; Kirsten Woodend - kwoodend@uottawa.ca

* Corresponding author

Published: 10 December 2008

Implementation Science 2008, 3:5 I doi:10.1 186/I748-5908-3-5I
Received: 8 October 2008

Accepted: 10 December 2008

This article is available from: http://www.implementationscience.com/content/3/I/5 I

(C) 2008 Gifford et al; licensee BioMed Central Ltd.

This is an Open Access article distributed under the terms of the Creative Commons Attribution License (http://creativecommons.org/licenses/by/2.0), which permits unrestricted use, distribution, and reproduction in any medium, provided the original work is properly cited.

\begin{abstract}
Background: Foot ulcers are a significant problem for people with diabetes. Comprehensive assessments of risk factors associated with diabetic foot ulcer are recommended in clinical guidelines to decrease complications such as prolonged healing, gangrene and amputations, and to promote effective management. However, the translation of clinical guidelines into nursing practice remains fragmented and inconsistent, and a recent homecare chart audit showed less than half the recommended risk factors for diabetic foot ulcers were assessed, and peripheral neuropathy (the most significant predictor of complications) was not assessed at all.

Strong leadership is consistently described as significant to successfully transfer guidelines into practice. Limited research exists however regarding which leadership behaviours facilitate and support implementation in nursing.

The purpose of this pilot study is to evaluate the impact of a leadership intervention in community nursing on implementing recommendations from a clinical guideline on the nursing assessment and management of diabetic foot ulcers.

Methods: Two phase mixed methods design is proposed (ISRCTN 12345678). Phase I: Descriptive qualitative to understand barriers to implementing the guideline recommendations, and to inform the intervention. Phase II: Matched pair cluster randomized controlled trial $(n=4$ centers) will evaluate differences in outcomes between two implementation strategies. Primary outcome: Nursing assessments of client risk factors, a composite score of 8 items based on Diabetes/Foot Ulcer guideline recommendations.

Intervention: In addition to the organization's 'usual' implementation strategy, a 12 week leadership strategy will be offered to managerial and clinical leaders consisting of: a) printed materials, b) one day interactive workshop to develop a leadership action plan tailored to barriers to support implementation; c) three post-workshop teleconferences.
\end{abstract}




\begin{abstract}
Discussion: This study will provide vital information on which leadership strategies are well received to facilitate and support guideline implementation. The anticipated outcomes will provide information to assist with effective management of foot ulcers for people with diabetes.
\end{abstract}

By tracking clinical outcomes associated with guideline implementation, health care administrators will be better informed to influence organizational and policy decision-making to support evidencebased quality care. Findings will be useful to inform the design of future multi-centered trials on various clinical topics to enhance knowledge translation for positive outcomes.

Trial Registration: Current Control Trials ISRCTN06910890

\section{Background: diabetic foot ulcers}

Diabetes mellitus, a complex, life-long metabolic disorder characterized by raised blood glucose concentrations, affects 4.2 percent of the world's population and over 1.5 million Canadians $[1,2]$. Ulceration of the foot is a significant problem for people with diabetes, affecting 15 percent at some time in their life $[3,4]$. Foot complications are a major reason for hospital admissions, accounting for approximately 20 percent of all diabetes-related admissions in North America [1]. Foot ulcers precede 85 percent of lower limb amputations $[4,5]$ and 30 percent of those undergoing amputation die within the following year [6]. Diabetes pathology that increases risk of foot ulcerations and complications includes peripheral neuropathy (impairment of nerve function), peripheral vascular disease, limited joint mobility and deformity $[1,4,5,7]$. The triad of neuropathy, deformity, and trauma is present in almost two thirds of people with foot ulcers [5] with footwear being a major cause of traumatic ulcers [8].

Lack of awareness of risk factors associated with diabetic foot ulcer by health care professionals and patients adds to unnecessary morbidity such as prolonged healing, infections and gangrene that may result in amputations $[4,5,9]$. Mills et al. (1991) reviewed records of 55 diabetic patients with localized gangrene or infection on a vascular surgical unit and found 29 percent were delayed in referral for definitive care due to a lack of recognition by practitioners of ischemia or an underestimation of the severity of infections [10].

Comprehensive assessments by health care professionals of risk factors are recommended in clinical practice guidelines for effective management and treatment of diabetic foot ulcers, and are supported by strong empirical evidence [1,4-7,11-16]. A recent Cochrane review showed managing ulcers with hydrogel dressings when compared to usual care (gauze dressings) improved healing rates by 23 percent at 12 to 20 weeks (95\% CI 10-36\%) [7]. Assessments are recommended to include: peripheral neuropathy, vascular status, structural deformities, infection and ulcer size $[1,5,9,12-15]$. Referrals to multidisci- plinary foot care specialists $[5,12,13]$ and patient education $[4,17]$ are equally emphasized.

\section{Problem: Implementing clinical guideline recommendations}

Clinical practice guidelines synthesize and translate high quality research evidence into recommendations for practice, and provide an easy and accessible tool for bridging the evidence-practice gap [18-21]. For practice change to occur however, guidelines must be utilized, and their timely and effective transfer into clinical practice remains fragmented and inconsistent [21-24]. Implementation strategies directed at individuals, the environment and the organizational context are necessary for successful implementation and practice change to occur [20,25-27]. In recent Cochrane reviews, tailored interventions that focus on individual and organizational barriers to change showed promise for implementing change and improving patient care [28], and interactive workshops were found to have moderately large effects on changing professional practice [29].

The importance of top managers' involvement and commitment in implementing innovations such as guidelines and change have been emphasized outside [30-39] and within healthcare settings [40-45]. Descriptive and qualitative evidence has identified leadership and management behaviours as having an important impact on nurses' work environments [42,46-50] and their use of research evidence to inform practice [27,51-63]. Similarly, a systematic review of 30 studies identified the lack of support from managers, and 'other staff' to be one of the greatest barriers to nurses' use of research [60]. Management behaviours such as support and commitment [56,58,64$69]$, policy revisions $[66,70]$ and monitoring of clinical outcomes [66,71] have been described as enablers to nurses' use of research [72]. Limited experimental research exists however regarding which behaviours are most effective to facilitate guideline implementation in nursing. A recent mixed methods study of 37 organizations found leadership to be the only predictor of sustained use of clinical guideline recommendations two and 
three years post-implementation, accounting for 47 percent of the variance $(p<.001)$ [73]. Using grounded theory to analyze 9 of the 37 organizations, Gifford et al. found patterns of leadership and managerial behaviours in organizations that sustained practice change based on guideline recommendations $(n=4)$ at 2 and 3 years differed when compared to organizations that did not sustain practice change $(n=5)$ [63]. A conceptual model was developed from the analysis that operationalizes leadership behaviours for implementing and sustaining practice change.

\section{Study Aim}

The aim of this pilot study is to evaluate the impact of a leadership intervention on implementing new recommendations from a clinical practice guideline on nursing assessments and management of foot ulcers for people with diabetes in community nursing practice. Specific objectives include:

1) To identify barriers and develop a tailored leadership intervention for home care nurse managers, supervisors, resource nurses and clinical staff to influence implementation of selected recommendations from the Registered Nurses Association of Ontario (RNAO) clinical practice guideline for care of foot ulcers for people with diabetes.

2) To determine the impact of the intervention on client, nurse and system outcomes.

3) To understand the feasibility of influencing leadership behaviours through the intervention.

4) To test and refine a model of leadership for implementing practice change.

We plan to test the following study hypotheses:

$\mathbf{H}_{1}$ : Nurses working in centers that receive the intervention will obtain significantly higher scores for practicing in accordance with guideline recommendations than control group.

$\mathbf{H}_{\mathbf{0}}$ : No change in group means will occur following the intervention.

\section{Design/Methods}

A two phase mixed method design is proposed (Figure 1). A pilot study is planned because there is little information regarding effective leadership behaviours for implementing practice change in nursing, and there is a need to test the intervention strategies prior to launching a larger multi-centered trial. Phase one involves descriptive qualitative methods to understand barriers to implementing the guideline recommendations and to refine the intervention strategy to be useful and appealing to leaders. A cluster randomized controlled trial, considered the optimal design when evaluating strategies to change professional behaviour $[20,74]$, will evaluate differences in outcomes between the two implementation strategies. Randomization will occur at the unit level to minimize threats of experimental contamination $[20,75,76]$.

Site

The research is being conducted in a home and community health-care service organization that provides nursing care through 23 centers in the province of Ontario Canada. The organization employs approximately 1500 nursing staff, 65 managers and supervisors, and 20 clinical resource nurses, and 7 clinical directors. Approximately 30 to 40 percent of clients receiving nursing services are diabetic, and clinical directors identified foot care for this population as a priority clinical topic, with a notable gap between current practices and guideline recommendations. For example no clients are currently being assessed for peripheral neuropathy the most significant predictor of ulcers, and recent chart audits indicated that co-morbidity, vascular status and wound size were not documented in at least 50 percent of charts for foot and leg ulcers. The organization has previously implemented clinical practice guidelines at an estimated cost of $\$ 60,000$ per implementation. To date implementation strategies have had mixed success. Implementation of the RNAO guideline Assessing and Managing Foot Ulcers for People with Diabetes [13] is planned in 2008 .

\section{Primary outcome}

Nursing assessments of client risk factors scores (NACRF), a composite score of 8 items based on recommendations from the Diabetes/Foot Ulcer guideline. The 8 items were chosen in consultation with clinical experts in diabetes and wound management, have a high level of research evidence for prediction of poor outcomes [13], and were reviewed for content validity by researchers and clinical experts in the field. Four of the eight items were previously used in a chart audit evaluation of another RNAO guideline related to the prevention of foot complications in people with diabetes $[77,78]$.

\section{Secondary outcomes}

1) proportion of people with healed ulcers at 12 weeks (defined as complete wound closure),

2) healing times in number of weeks,

3) types of treatments used (eg: hydrogel dressings, sharp debridement, offloading devices),

4) referral rates to specialists services,

5) documented patient education, 


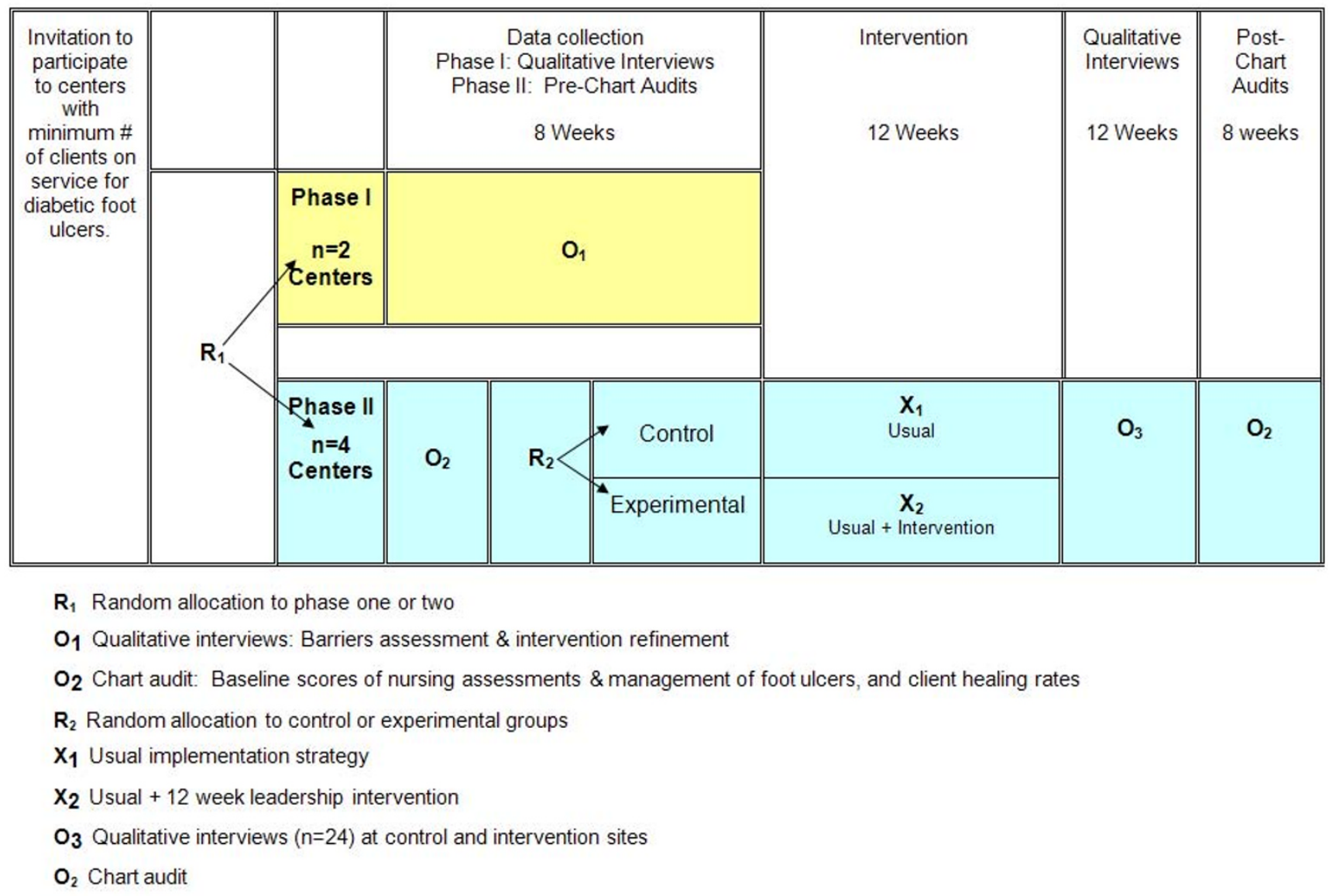

Figure I

Design: Two phased mixed methods pilot study.

6) proportion clients assessed for all items in the NACRF scale (all-or-none measure) [79],

7) Nursing participant satisfaction and perceived utility of elements of the intervention.

\section{Sample}

All centers (approximately 10) with the minimum number of clients being treated for diabetic foot ulcers to satisfy sample size calculations will be invited to participate in the study. Two centers will be randomly assigned to participate in phase one and four will be randomly assigned for phase two. The four sites in phase two will be randomly allocated to control $(\mathrm{n}=2)$ or experimental ( $\mathrm{n}$ $=2$ ) groups.

\section{Sample size}

Sample size calculations were determined, and are based on the use of an independent t-test on NACRF scores at the end of the study. The following assumptions have been made: alpha $=.0 .05$ (two-tailed), Beta $=0.20$ and an expected change in NACRF scores of 20 percent. Although all items within the NACRF have not been previously used, four were previously evaluated in a pre/post chart audit that showed a 26 percent absolute improvement in nursing documentation (range -3.6 to 57.1 ) [78]. Thus, an estimate of 20 percent improvement will be used. In addition, standard deviations (SD) and intra-cluster correlation coefficients (ICCs $=\rho$ ) for NACRF are presently unknown. It is however, estimated that the effect size may be as small as 1.00 but to be conservative $0.83(\mathrm{SD}=3)$ is assumed for this calculation. Based on these assumptions, 30 charts will be needed in both intervention and control groups $(n=60)$. While it is not known exactly how many clients with diabetes will be on service for foot ulcers during the study period, senior administrators have reassured investigators that a minimum of 30 clients per group is feasible.

\section{Power estimates for secondary outcomes}

The anticipated rate of healing in the control group is 24 percent in 12 weeks [16]. For the proportion of ulcers 
healed and healing times, 30 charts in control and intervention groups would yield 80 percent power to detect an absolute increase in healing rates of 40 percent (alpha .05, two tailed). The study is also powered to detect an absolute increase of 40 percent in referral rates and patient education, also measured as a proportion.

\section{Data Collection}

Baseline

All adult clients (18 years or older) diagnosed with Type 1 or Type 2 diabetes being treated for a first or recurring foot ulcer(s) will be eligible for the study. Using data abstraction forms modified from a previous guideline evaluation project [77], chart audits will be performed at control and experimental sites prior to randomization until sample size is achieved or up to 12 weeks prior to the intervention. Chart audit data collectors will be trained and supervised by researchers with experience in conducting chart audits. Interrater and test-retest reliability will be assessed in a random review of 10 percent of charts.

\section{PHASE I: Barriers Assessment and Intervention Development}

Semi-structured interviews will be conducted at two centers with a sample of managers, supervisors, resource nurses and 2 'preceptor' staff nurses from each site $(\mathrm{n}=$ 10). Preceptor staff are experienced clinical nurses who volunteer to provide support to novice or newly hired nurses regarding clinical issues. The interview guide is based on previously published guides for assessing barriers and supports [80], and has been structured to understand components of an intervention strategy considered useful to managers and clinical leaders. Results of phase I will inform content and structure of the intervention strategy.

\section{PHASE II: Intervention Strategy Control Group}

Staff at each center will receive the 'usual' guideline implementation strategy consisting of: 1) a formal guideline launch; 2) self-directed learning package, 3) educational sessions for staff related to the clinical application of practice recommendations. Senior administrators estimated that approximately 70 percent of staff typically attend 'usual' strategies.

\section{Experimental Group}

In addition to the 'usual' implementation strategy, a 12 week leadership strategy will be offered to mangers, supervisors, resource nurses, and 2 preceptor staff from each center to facilitate and support implementation, consisting of:

1) Mailed package of printed materials: to include study purpose; summary of recommendations, models of lead- ership and planned change; literature article; three questions to assess barriers to nurses assessing and managing foot ulcers in accordance to the guideline recommendations. Review time: approx 15-30 minutes.

2) Interactive workshop (one day): Content and activities will be tailored to results of phase one, planned to include: a) evidence and theory on leadership and implementing practice change; b) focus group discussions about barriers to implementing the recommendations; $\mathrm{c}$ ) role playing exercises; and d) facilitated development of a team leadership implementation plan for each center, tailored to identified barriers.

3) Post-workshop teleconferences: (2, 6, and 10 weeks after workshop) to provide a forum for questions, discussions and networking amongst participants.

\section{Guiding Theoretical Framework}

The theoretical underpinnings of the proposed intervention are based on mechanisms of planned change as described in the Ottawa Model of Research Use $\left(\mathrm{OMRU}^{\odot}\right)$ [52,81], effective leadership behaviours described by Yukl [82], and leadership for guideline implementation described by Gifford et al [63].

The OMRU is a planned change framework for knowledge transfer in health care delivery [52]. Derived from evidence and theories of change, the OMRU recognizes that practice change is not a linear process, but involves simultaneous and interactive relationships between the nature of the innovation, the potential adopters, and the context within the practice environment. Three key processes involved are: 1) assessing barriers and supports; 2) developing and monitoring interventions tailored to barriers and supports; 3) evaluating outcomes. The underlying mechanism is that tailoring intervention strategies to address barriers and strengthen supports related to the innovation, potential adopters and practice environment will result in practice change.

The OMRU provides a template to assess barriers and supports for implementing change and will facilitate the selection of intervention strategies with the best probability of success. The relevance and pragmatic utility of the OMRU for guiding implementation of innovations (including nursing guidelines) has been demonstrated in previous research [83-87].

Leadership is "the process of influencing others to understand and agree about what needs to be done and how to do it, and the process of facilitating individual and collective efforts to accomplish shared objectives" [[82], p.8]. Three meta-categories of effective leadership behaviours described by Yukl and supported by decades of research 
[82,82,88,89], provide the foundation for this study: 1) relations-orientated, 2) change-orientated and 3) task-orientated. Relations-oriented behaviours include supporting, developing personal skills and job adjustments, and recognizing others and their contributions. Relations-oriented behaviours increase mutual trust, cooperation among members, and commitment to a unit and organization. Change-oriented behaviours are concerned with integrating a vision, developing strategies and building coalitions to support change, creating a sense of need and demonstrating commitment to change. Task-oriented behaviours include clarifying roles, monitoring operations and performance, and the efficient use of resources [82].

Three leadership themes emerged as central to implementing guidelines in the grounded theory study by Gifford et al., and these align closely with Yukl's [82] metacategories of effective leadership behaviours. Leaders were found to have: 1) facilitated staff through relationsoriented behaviours (e.g.: support, encouragement and recognition); 2) created a positive milieu within the clinical practice environment through change-related behaviours (e.g.: reinforced goals and philosophies of care); and 3 ) influenced organizational structures and processes through task-oriented behaviours (e.g.: providing resources, policies and monitoring). Together these behaviours influenced individuals, practice environments and infrastructures to enable nurses to practice based on guideline recommendations.

Drawing on the work of Van de Ven et al. (1999), effective leadership at different hierarchical levels is necessary for the adoption of new innovations in organizations [90]. Successful implementation in healthcare is dependent on strong effective leadership to create a context which is receptive to change $[26,27,51,63,82,90-96]$. The organizational context exerts a particularly powerful set of influences on nurses' adoption of new innovations $[81,97,98]$. Extensive managerial involvement, commitment and attitude toward change, role clarity, and leadership styles are significantly associated with maintaining the momentum of innovation adoption in organizations $[32,33,90,99,100]$. A 'road map" that explains what leaders do is not however possible due to the inherent unpredictability and nonlinear processes of innovation adoption [90]. "Management cannot ensure innovation success but can influence its odds" (p.11, 88). Leadership is an integral part of managerial roles, and is necessary for managers to influence change $[34,82,96,101-104]$. Individuals and organizational context must be influenced for practice change to occur based on new innovations [20]. The proposed intervention aims to influence individuals, the practice environment and organizational context through leadership processes and behaviours that manage barriers and enable practice change to occur. (Figure 2)

\section{Post-intervention measures}

Chart audits will be conducted on all patients being treated for diabetic foot ulcers up to 12 weeks following the intervention. To understand the leadership and management behaviours that influenced nursing practice, semi structured qualitative interviews will be conducted with managers, supervisors and resource nurses and staff nurses at control and experimental sites $(n=20)$. The experimental group interview guide will also ask for participants' opinions regarding the usefulness of the intervention. The interview guides are based on previously published guides for assessing barriers and supports [80], and previous research on implementing guidelines [105]. To evaluate satisfaction and perceived utility of the one day workshop, an evaluation form, based on previously evaluations from RNAO guideline implementations, [106] will be administered at the end of the workshop.

\section{Data Analysis}

Pre/post univariate descriptive data will be computed for demographics of patients and staff.

\section{Primary Outcome: Composite NACRF scores}

Eeach item within the scale will be coded dichotomously ( $1=$ yes; $0=$ no), and a total score calculated out of 8 . Bivariate analysis using independent groups t-tests will be conducted to assess the significance of differences pre/ post intervention between control and experimental groups. The alpha level will be pre-set at .05, and 95 percent confidence intervals calculated. An 'intent to treat' analysis will be used [75].

\section{Secondary Outcomes}

The proportion of people with healed ulcer(s) at 12 weeks, and time to complete healing will be calculated. Types of treatments used (eg: hydrogel dressings, sharp debridement, offloading devices) will be calculated. Clients with documented patient education and referrals will be dichotomously coded ( $1=$ yes; $0=$ no/don't know). Independent groups t-tests for continuous variables, and chi squares for categorical variables will determine differences before and after the intervention within each center, and between control and experimental groups. Descriptive statistics will be used to evaluate nursing participants' satisfaction and perceived utility with the elements of the intervention.

\section{Other Outcomes}

ICCs $(\rho)$ will be calculated on pre/post measures of composite NACRF scores, and demographic characteristics of clients (e.g.: age, gender) [107]. Matching is expected to minimize between-unit variations, and previous research 
Figure 2: Conceptual Framework

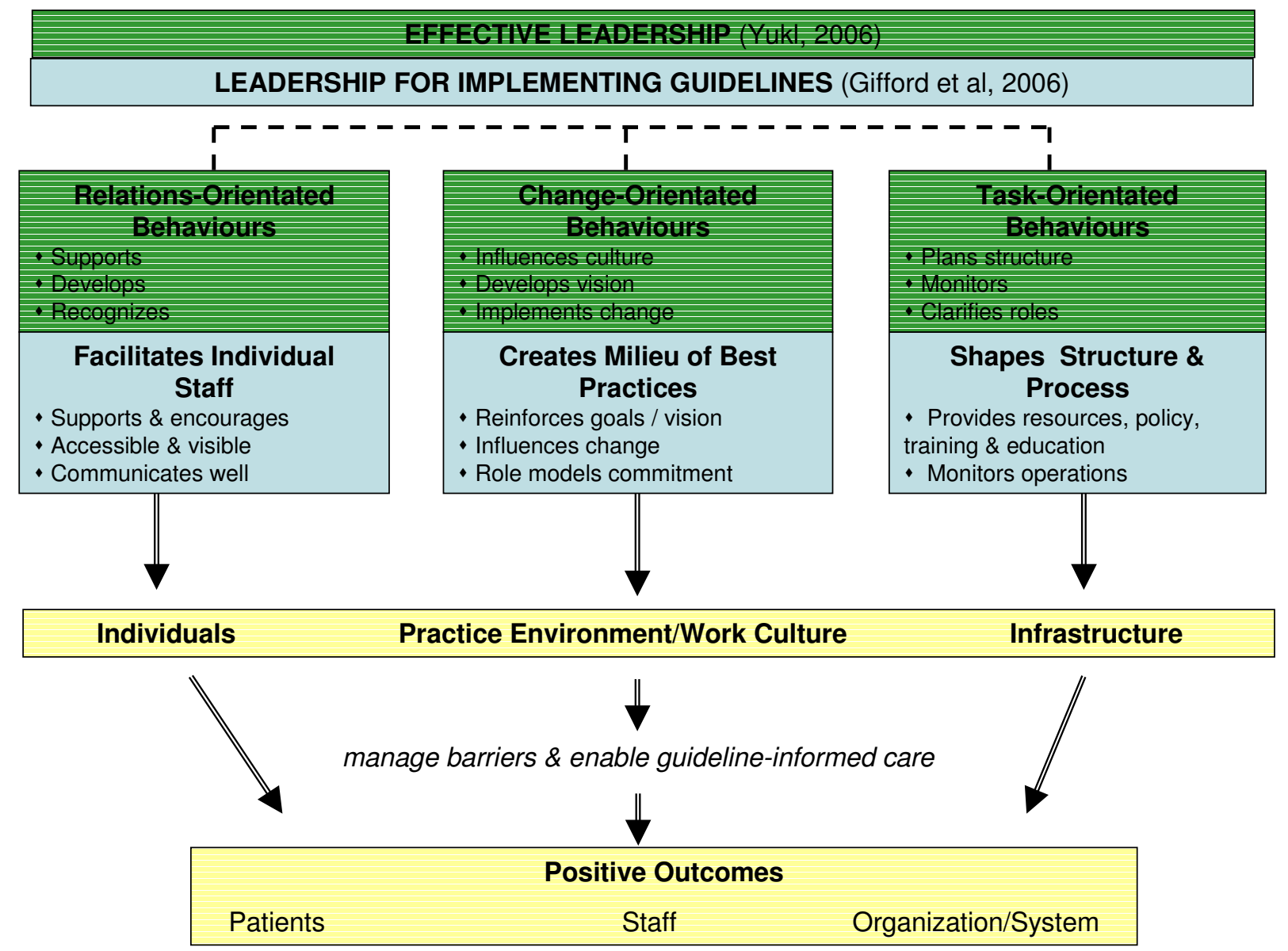

Figure 2

Conceptual Framework.

shows ICCs for the process of care to be high $[20,74,108]$. ICCs from this study will be useful to inform future studies regarding sample size calculations $[107,109,110]$.

\section{Qualitative Findings}

To understand how the intervention influenced leadership practices, data from qualitative interviews will be audio-taped, transcribed, entered into qualitative software (NVIVO) and analyzed using content analysis techniques involving an iterative process of data reduction, data display, conclusion drawing and verification [111].

\section{Discussion}

\section{Limitations}

An inherent limitation of collecting data through chart audit is the documented data obtained may potentially underestimate actual care [112]. Other methods of data collection, such as direct observations are not feasible for this pilot study due to geographical distances and associated costs of observing home-care nurses provide care in patients' homes throughout the province. A second limitation of collecting data through chart audits involves reviewers accuracy, impartiality, attentiveness and consistency in extracting data [112]. Having an experienced research manager overseeing the process, and pilot testing for interrater and test-retest reliability will assist with addressing this limitation. Additionally, this is a pilot study and not sufficiently powered to account for the effect of clustering.

\section{Ethical Considerations}

Prior to commencement, ethical approval will be obtained from University of Ottawa Research Ethics Board which follows Tri-council guidelines [113]. Details of ethical considerations, including informed consent, anonymity and confidentiality are found in ethics submission 
form. Briefly, a numerical coding system will be used to track individual participant and chart audit data. Names of interview participants will be kept separated from data collection forms and locked at the University of Ottawa Nursing Best Practice Research Unit. Names from chart audits will be kept by the research manager at the participating organization in a secured place; only numerically coded data will be sent to investigators. Only aggregated data will be reported. Information consent forms will be available in English and French. Data will be securely stored for 5 years after study conclusion (e.g. December, 2014).

\section{Feasibility}

This study aligns with the participating organization's timeline to implement the Diabetes/Foot Ulcer BPG, and has been developed in consultations with senior administrators to ensure feasibility, support, and compatibility with organizational direction, initiatives and training strategies.

\section{Potential Impact on Nursing Care}

This pilot study will contribute to the development of leadership strategies to facilitate implementation of guideline recommendations on a priority clinical topic in community nursing. The anticipated outcome is information to assist with more effective management and faster healing of foot ulcers in community health nursing for people with diabetes. With the high cost of guideline implementation, this study will provide vital information on which strategies are well received when implementing practice change. By tracking clinical outcomes associated with guideline use, nursing administrators will be better informed to influence organizational and policy decisions to support high quality nursing care. Findings will be useful to inform the design of future multi-centered trials on various clinical topics, and to enhance the science of knowledge translation for evidence-informed practice change that impacts quality nursing care and client outcomes.

\section{Competing interests}

The authors declare that they have no competing interests.

\section{Authors' contributions}

WG and BD conceptualized the study. WG led the writing and application for funding. All other authors contributed to conceptualizing based on specific areas expertise: IG for knowledge translation framework and tool development; NL for organizational feasibility and data collection methods; AT for leadership development theory and leadership outcomes; KW for quantitative methodology and power analysis. All authors have read drafted versions of the manuscript, provided input and refinements, and agreed to the final manuscript.

\section{Acknowledgements}

Gifford is a doctoral student at the University of Ottawa, Ontario Canada through support from the University of Ottawa Excellence Scholarship and Registered Nurses Association of Ontario Doctoral Fellowship. This study is funded through a research grant from the Canadian Nurses' Foundation Nursing Care Partnership Fund and the Ministry of Health and Long Term Care of Ontario Nursing Research Fund.

\section{References}

I. Canadian Diabetes Association 2003 Clinical Practice Guidelines for the Prevention and Management of Diabetes in Canada [http://www.diabetes.ca/cpg2003/chapters.aspx?agrowing healthcareproblem.htm]

2. Canadian Diabetes Association (CDA): Clinical practice guidelines for the management of diabetes in Canada. Canadian Medical Association Journal 1998, 159:SI-S29.

3. Spencer S: Pressure relieving interventions for preventing and treating diabetic foot ulcers. Cochrane Database Syst Rev 2000:CD002302.

4. Valk GD, Kriegsman DM, Assendelft WJ: Patient education for preventing diabetic foot ulceration. Cochrane Database Syst Rev 2005:CD00I488.

5. Boulton AJ, Kirsner RS, Vileikyte L: Neuropathic diabetic foot ulcers. New England Journal of Medicine 2004, 35 I:48-55.

6. Diabetes and peripheral vascular disease Chapter 6. In Diabetes in Ontario an ICES practice atlas [http://www.ices.on.cal file/DM Chapter6.pdf]

7. Smith J: Debridement of diabetic foot ulcers (Cochrane Review). Cochrane Database Syst Rev 2002:CD003556.

8. Birke JA, Patout CA Jr, Foto JG: Factors associated with ulceration and amputation in the neuropathic foot. Journal of Orthopaedic and Sports Physical Therapy 2000, 30:91-97.

9. Boulton AJ, Meneses P, Ennis W]: Diabetic foot ulcers: A framework for prevention and care. Wound Repair and Regeneration 1999, 7:7-16.

10. Mills JL, Beckett WC, Taylor SM: The diabetic foot: consequences of delayed treatment and referral. Southern Medical Journal 1991, 84:970-974.

II. Registered Nurses Association of Ontario Nursing Best Practice Guidelines Project: Reducing foot complications for people with diabetes Toronto, Ontario, Canada: Registered Nurses Association of Ontario; 2004.

12. Mclntosh A, Peters J, Young R, Hutchinson A, Chiverton R, Clarkson $S$, et al.: Prevention and management of foot problems in Type 2 diabetes: Clinical Guidelines and evidence Sheffield: University of Sheffield; 2003.

13. Registered Nurses Association of Ontario: Assessment and management of foot ulcers for people with diabetes Toronto, Canada: Registered Nurses Association of Ontario; 2005.

14. Orsted HL, Searles G, Trowell H, Shapera L, Miller P, Rahman J: Best practice recommendations for the prevention, diagnosis and treatment of diabetic foot ulcers: Update 2006. Adv Skin Wound Care 2006, 20(1 2):655-669.

15. Sibbald RG, Orsted HL, Coutts P, Keast D: Best Practice recommendations for preparing the wound bed: Update 2006. Adv Skin Wound Care 2006, 20(7):390-405.

16. Margolis DJ, Kantor J, Berlin JA: Healing of diabetic neuropathic foot ulcers receiving standard treatment. A meta-analysis. Diabetes Care 1999, 22:692-695.

17. Valk GD, Kriegsman DM, Assendelft WJ: Patient education for preventing diabetic foot ulceration. A systematic review. [Review] [44 refs]. Endocrinology \& Metabolism Clinics of North America 2002, 3 I:633-658.

18. Ciliska DK, Pinelli J, DiCenso A, Cullum N: Resources to enhance evidence-based nursing practice. AACN Clinical Issues 200I, 1 2:520-528.

19. Davies BL: Sources and models for moving research evidence into clinical practice. JOGNN - Journal of Obstetric, Gynecologic, \& Neonatal Nursing 2002, 3 1:558-562.

20. Grol R, Wensing M, Eccles M: Improving patient care The implementation of change in clinical practice Edinburgh: Elsevier Butterworth Heinemann; 2005.

21. Grol R: Successes and failures in the implementation of evidence-based guidelines for clinical practice. Medical Care 200I, 39:1146-II54. 
22. Browman GP, Snider A, Ellis P: Negotiating for change. The healthcare manager as catalyst for evidence-based practice: changing the healthcare environment and sharing experience. Healthcarepapers 2003, 3:10-22.

23. Cabana MD, Rand CS, Powe NR, Wu AW, Wilson MH, Abboud PA, et al: Why don't physicians follow clinical practice guidelines?: A framework for improvement. Journal of the American Medical Association 1999, 282:|458-|465.

24. Davis DA, Taylor-Vaisey A: Translating guidelines into practice: A systematic review of theoretic concepts, practical experience and research evidence in the adoption of clinical practice guidelines. CMAJ 1997, I57:408-416.

25. Grimshaw JM, Thomas RE, MacLennan G, Fraser C, Ramsay CR, Vale $L$, et al.: Effectiveness and efficiency of guideline dissemination and implementation strategies. Health Technol Assess 2004 8(6): iii-iv, I-72.

26. Dobbins M, Ciliska D, Cockerill R, Barnsley J, DiCenso A: A framework for the dissemination and utilization of research for health-care policy and practice. Online Journal of Knowledge Synthesis for Nursing 2002, 9:7.

27. Stetler CB, Brunell M, Giuliano KK, Morsi D, Prince L, Newell-Stokes $\mathrm{V}$ : Evidence-based practice and the role of nursing leadership. Journal of Nursing Administration 1998, 28:45-53.

28. Shaw B, Cheater F, Baker R, Gillies C, Hearnshaw H, Flottorp S, et al: Tailored interventions to overcome identified barriers to change: effects on professional practice and health care outcomes (Review). Cochrane Database Syst Rev 2005:CD005470.

29. Thomson O'Brien M, Freemantle N, Oxman A, Wolf F, Davis D, Herrin J: Continuing education meetings and workshops: effects on professional practice and health care outcomes (Review). Cochrane Database Syst Rev 2001:CD003030.

30. Burpitt WJ, Bigoness WJ: Leadership and innovation among teams The impact of empowerment. Small group research 1997 28:4|4-423.

31. Dackert I, Loov LA, Martensson M: Leadership and climate for innovation in teams. Economic and Industrial Democracy 2004 25:301-318.

32. Damanpour F: Organizational innovation: A meta-analysis of effects of determinants and moderators. Academy of management journal 1991, 34:555-588.

33. Elenkov DS, Manev IM: Top management leadership and influence on innovation: The role of sociocultural context. Journal of management 2005, 3 I:38I-402.

34. Hoffman RC, Hegarty WH: Top management influence on innovations: Effects of executive characteristics and social culture. Journal of management 1993, 19:549-574.

35. Howell JM, Avolio BJ: Transformational leadership, transactional leadership, locus of control, and support for innovation: Key predictors of consolidated-business-unit performance. Journal of Applied Psychology 1993, 78:89|-902.

36. Mumford M, Licuanan B: Leading for innovation: Conclusions, issues, and directions. [References]. Leadership Quarterly 2004, | 5:Feb04-I7|.

37. Waldman DA, Bass BM: Transformational leadership at different phases of the innovation process. The Journal of High Tech nology Management Research I991, 2:169-180.

38. West MA, Borrill CS, Dawson JF, Brodbeck F, Shapiro DA, Haward $B$ : Leadership clarity and team innovation in health care. The Leadership Quarterly 2003, I 4:393-4I0.

39. Vance C, Larson E: Leadership research in business and health care. Journal of Nursing Scholarship 2002, 34:I65-I7I.

40. Baker GR: Identifying and assessing competencies: A strategy to improve healthcare leadership. Healthcare Papers 2003 3:49-58.

41. Leatt P, Porter J: Where are the healthcare leaders? The need for investment in leadership development. Healthcare Papers 2003, 4:|4-3|.

42. Keeping patients safe: Transforming the work environment of nurses. . [retrieved April 9, 2005]

43. Iles V, Sutherland K: Organizational change: A review for health care managers, professionals and researchers. National Co-ordinating Centre for NHS Service Delivery and Organization R\&D 2001: I- 100 .

44. Hartman SJ, Crow SM: Executive development in healthcare during times of turbulence Top management perceptions and recommendations. Journal of Management in Medicine 2002 , 16:359-370

45. Weingart SN, Page D: Implications for practice: Challenges for healthcare leaders in fostering patient safety. Quality Safety Health Care 2004, I3:52-56.

46. Havens D, Aiken L: Shaping Systems to Promote Desired Outcomes: The Magnet Hospital Model. Journal of Nursing Administration 1999, 29: I4-20.

47. Laschinger HKS, Wong C, McMahon L, Kaufmann C: Leader behavior impact on staff nurse empowerment, job tension, and work effectiveness. Journal of Nursing Administration 1999 , 29:28-39.

48. Gleason Scott J, Sochalski J, Aiken L: Review of magnet hospital research Findings and implications for professional nursing practice. Journal of Nursing Administration 1999, 29:9-19.

49. De Groot HA: Evidence-based leadership: Nursing's new mandate. Nurse Leader 2005:37-4I.

50. Manion J: Supporting nurse managers in creating a culture of retention. Nurse Leader 2005, 3:52-56.

51. McCormack B, Kitson A, Harvey G, Rycroft-Malone J, Titchen A, Seers K: Getting evidence into practice: the meaning of 'context'. Journal of Advanced Nursing 2002, 38:94-104.

52. Graham ID, Logan J: Innovations in knowledge transfer and continuity of care. Canadian Journal of Nursing Research 2004, 36:89-103.

53. Kitson A, Harvey G, McCormack B: Enabling the implementation of evidence based practice: a conceptual framework. Quality in Health Care 1998, 7:149-158.

54. Angus J, Hodnett E, O'Brien-Pallas L: Implementing evidencebased nursing practice: a tale of two intrapartum nursing units. Nursing Inquiry 2003, 10:218-228.

55. Udod SA, Care WD: Setting the climate for evidence-based nursing practice: what is the leader's role? Canadian Journal of Nursing Leadership 2004, I 7:64-75.

56. Rycroft-Malone J, Harvey G, Seers K, Kitson A, McCormack B, Titchen A: An exploration of the factors that influence the implementation of evidence into practice. Journal of Clinical Nursing 2004, I 3:913-924.

57. Funk SG, Champagne MT, Wiese RA, Tornquist EM: BARRIERS: The Barriers to research utilization scale. Applied Nursing Research 1991, 4:39-45.

58. Parahoo K: Barriers to, and facilitators of, research utilization among nurses in Northern Ireland. Journal of Advanced Nursing 2000, 3 I:89-98.

59. Thompson C, McCaughan D, Cullum N, Sheldon TA, Mulhall A Thompson DR: The accessibility of research-based knowledge for nurses in United Kingdom acute care settings. Journal of Advanced Nursing 200 I, 36: I |-22.

60. Hutchinson AM, Johnston L: Beyond the BARRIERS Scale Commonly reported barriers to research use. Journal of nursing administration 2006, 30:189-199.

61. Bryar RM, Closs SJ, Baum G, Cooke J, Griffiths J, Hostick T, et al.: The Yorkshire BARRIERS project: diagnostic analysis of barriers to research utilisation. International Journal of Nursing Studies 2003, 40:73-84.

62. Lapierre E, Ritchey K, Newhouse R: Barriers to research use in the PACU. J Perianesth Nurs 2004, I 9(2):78-83.

63. Gifford WA, Davies B, Edwards N, Graham ID: Leadership strategies to influence the use of clinical practice guidelines. Canadian Journal of Nursing Leadership 2006, 19:72-87.

64. Camiah S: Utilization of nursing research in practice and application strategies to raise research awareness amongst nurse practitioners: a model for success. Journal of Advanced Nursing 1997, 26: I 193-1202.

65. Hatcher S, Tranmer J: A survey of variables related to research utilization in nursing practice in the acute care setting. Canadian Journal of Nursing Administration 1997, 1 0:3 | -53.

66. Rutledge D, Donaldson N: Building organizational capacity to engage in research utilization. Journal of Nursing Administration 1995, 25:12-16.

67. Tsai SL: Nurses' participation and utilization of research in the Republic of China. International Journal of Nursing STudies 2000, 3:435-444.

68. Closs C, Cheater FM: Evidence for nursing practice: A clarification of the issues. Journal of Advanced Nursing 1999, 30:10-17. 
69. Kajermo KN, Nordstrom G, Krusebrant A, Lutzen K: Nurses' experiences of research utilization within the framework of an educational programme. Journal of Clinical Nursing 200I, |0:67|-68|.

70. Harrow D, Foster J, Greenwood J: Evidence and leadership: the tools for change. Contemporary Nurse 200I, I I:9-17.

7I. Wallin L, Bostrom A, Harvey G, Wikblad K, Ewald U: National guidelines for Swedish neonatal nursing care: evaluation of clinical application. International Journal for Quality in Health Care 2000, I 2:465-474.

72. Gifford W, Davies B, Edwards N, Griffin P, Lybanon V: Managerial leadership for nurses' use of research evidence: an integrative review of the literature. [Review] [79 refs]. Worldviews on Evidence-Based Nursing 2007, 4: I 26-145.

73. Davies B, Edwards N, Ploeg J, Virani T, Skelly M, Dobbins M: Determinants of the Sustained Use of Research Evidence in Nursing Final Report Nursing Best Practice Research Unit, Funded by Canadian Health Services Research Foundation; 2006.

74. Research: Cluster randomised trials [http://www.abdn.ac.uk/ hsru/research/del of care/professionals behaviour/cluster/]

75. Shadish WR, Cook TD, Campbell DT: Experimental and quasi-experimental designs for generalized causal inference Boston: Houghton Mifflin Company; 2002

76. Donner A, Klar N: Design and analysis of cluster randomization trials in health research London: Arnold Publishers; 2000.

77. RNAO Evaluation Team - Nursing Best Practice Guidelines Project, Cycle 3: Reducing foot complications for people with diabetes Evaluation Tools [http://www.rnao.org/Storage/ 12/635 BPG foot diabetes eval.pdf]

78. Edwards N, Davies B, Dobbins M, Griffin P, Ploeg J, Skelly J: Evaluation Summary: Reducing Foot Complications for People with Diabetes 2003.

79. Nolan T, Berwick DM: All-or-none measurement raises the bar on performance. JAMA 1908, 295: I I68-1 I70.

80. Edwards N, Davies B, Griffin P, Ploeg J, Skelly J, Danseco E, et al: Evaluation of nursing best practice guidelines: Interviewing nurses and administrators 2004 [http://www.rnao.org/Storage//3/ 778 CHRU Monograph Series M04-I.pdf]. CHRU Publication No. M04-I edn. Ottawa, ON: Community Health Research Unit, University of Ottawa

8I. Logan J, Graham ID: Toward a comprehensive interdisciplinary model of health care research use. Science Communication 1998, 20:227-246

82. Yukl GA: Leadership in organizations 6th edition. Upper Saddle River, NJ: Pearson Prentice Hall; 2006.

83. Graham K, Logan J: Using the Ottawa Model of Research Use to implement a skin care program. [Review] [26 refs]. Journal of Nursing Care Quality 200I.

84. Logan J, Harrison MB, Graham I, Dunn K, Bissonnette J: Evidencebased pressure-ulcer practice: The Ottawa Model of Research Use. Canadian Journal of Nursing Research 1999, 3 I:37-52.

85. Stacey D, Graham ID, O'Connor AM, Pomey M: Barriers and facilitators influencing call center nurses' decision support for callers facing values-sensitive decisions: a mixed methods study. Worldviews on Evidence-Based Nursing 2005, 2: 184-195.

86. Hogan DL, Logan J: The Ottawa Model of Research Use A guide to clinical innovation in the NICU. Clinical Nurse Specialist 2004, 18:255-261.

87. Lorimer $\mathrm{K}$ : Continuity through best practice: design and implementation of a nurse-led community leg-ulcer service. Canadian Journal of Nursing Research 2004, 36: I05-I I2.

88. Yukl G: An Evaluative Essay on Current Conceptions of Effective Leadership. European Journal of Work and Organizational Psychology 1999, 8:33-48.

89. Yukl G, Gordon A, Taber T: A hierarchical taxonomy of leadership behavior: Integrating a half century of behavior research. Journal of Leadership \& Organizational Studies 2002, 19:15-32.

90. Ven AH Van de, Polley DE, Garud R, Venkataraman S: The innovation journey New York: Oxford University Press; 1999.

91. Redfern S, Christian S: Achieving change in health care practice. Journal of Evaluation in Clinical Practice 2003, 9:225-238.

92. Udod SA, Care WD: Setting the climate for evidence-based nursing practice: What is the leader's role? Nursing Leadership 2004, 17:64-75.
93. Dopson S, Fitzgerald L, Ferlie E, Gabbay J, Locock L: No magic targets! Changing clinical practice to become more evidence based. Health Care Management Review 2002, 27:35-47.

94. Stetler CB: Role of the organization in translating research into evidence-based practice. Outcomes Management 2003, 7:97-103.

95. Iles V, Sutherland K: Organisational change. A review for health care managers, professionals and researchers London: National Co-ordinating Centre for NHS Service Delivery and Organisation R \& D; $200 I$.

96. Swayne LE, Duncan WJ, Ginter PM: Strategic management of health care organizations fifth edition. Malden, MA: Blackwell Publishing; 2006.

97. Royle J, Blythe J, Ciliska D, Ing D: The organizational environment and evidence-based nursing. Canadian Journal of Nursing Leadership 2000, 13:31-37.

98. Estabrooks C: Translating research into practice: Implications for organizations and administrators. Canadian Journal of Nursing Research 2003, 35:53-68.

99. Greenhalgh T, Robert G, Macfarlane F, Bate P, Kyriakidou O: Diffusion of innovations in service organizations: Systematic review and recommendations. The Millbank Quarterly 2004, 82:58I-629.

100. West M, Borrill C, Dawson J, Brodbeck F, Shapiro D, Haward B: Leadership clarity and team innovation in health care. [References]. Leadership Quarterly 2003, 14:

101. Hamlin RG, Cooper DJ: Identifying the criteria of managerial and leadership effectiveness within the Brimingham Women's Healthcare NHS Trust through HRD professional partnership research, WPIOI/04 edn University of Wolverhampton; 2004.

102. Hamlin RG: A study and comparative analysis of managerial and leadership effectiveness in the National Health Service: an empirical factor analytic study within an NHS Trust hospital. Health Services Management Research 2002, 15:245-263.

103. Dackert I, Loov LA, Martensson M: Leadership and climate for innovation in teams. Economic and Industrial Democracy 2004, 25:30I-3I8

104. Waldman DA, Bass BM: Transformational leadership at different phases of the innovation process. The Journal of High Technology Management Research I99I, 2:169-I80.

105. Davies B, Edwards N, Griffin P, Dobbins M, Ploeg J, Skelly J, et al.: Research Proposal: Determinants of the sustained use of research evidence in nursing Canadian Health Services Research Fund (CHSRF); 2002.

106. Edwards N, Davies B, Danesco E, Brosseau L, Pharand D, Ploeg J, et al.: Evaluation of nursing best practice guidelines: perceived worth and educational/supportive processes, CHRU No. M04-3 edn Ottawa, Ontario: Community Health Research Unit University of Ottawa; 2004.

107. Campbell MK, Grimshaw JM, Elbourne DR: Intracluster correlation coefficients in cluster randomized trials: empirical insights into how should they be reported. BMC Medical Research Methodology 2004, 4:9.

108. Littenberg B, MacLean CD: Intra-cluster correlation coefficients in adults with diabetes in primary care practices: the Vermont Diabetes Information System field survey. BMC Med Res Methodol 2006, 6:20.

109. Cosby RH, Howard M, Kaczorowski J, Willan AR, Sellors JW: Randomizing patients by family practice: sample size estimation, intracluster correlation and data analysis. Fam Pract 200I, 20(I):77-82. $2003 \mathrm{Feb}$

110. Killip S, Mahfoud Z, Pearce K: What is an intracluster correlation coefficient? Crucial concepts for primary care researchers. Annals of Family Medicine 2004, 2:204-208.

III. Miles M, Huberman A: Qualitative Data Analysis: An expanded sourcebook second edition. Thousand Oaks, California: SAGE Publications Inc; 1994.

1 12. Wu L, Ashton CM: Chart review. A need for reappraisal. Eval Health Prof 1997, 20(2): | 46-163.

113. Canadian Institutes of Health Research Natural Sciences and Engineering Research Council of Canada Social Sciences and Humanities Research Council of Canada: Tri-Council Policy Statement: Ethical Conduct for Research Involving Humans, (with 2000, 2002, 2005 amendments) edn 1998. 